\title{
MONITORING OCEANIC EARTHQUAKES WITH SOSUS: AN EXAMPLE FROM THE CARIBBEAN
}

\author{
By C.J. Bryan and C.E. Nishimura
}

T-phases are

acoustic signals in

which the primary

portion of the

propagation path is

through the oceans.
$\mathbf{T}$ -PHASES IRE acoustic signals in which the primary portion of the propagation path is through the oceans. Energy sources resulting in the generation of $\mathrm{T}$-phases include earthquakes, submarine rolcanism. and underwater explosions. Once seismic energy is coupled into the water column. T-phases propagate as compressional waves primarily through the Sound Fixing and Ranging (SOFAR) Channel, and may be reconverted, at continental shelves. into short-period elastic waves that travel through the sediments and basement of the continents. The wave-guide effect of the sound channel combined with the low attenuation of sound in seawater permit T-phases to propagate over great distances through the oceans. It is this fundamental property of T-phases that make them ideal for the study of low-magnitude seismicity within the oceans. The frequency content of T-phases $(1->10() \mathrm{Hz})$ is such that attenuation within the crust and upper mantle precludes long-range inland propagation: therefore. the best instruments for the detection and analysis of $T$-phases are underwater hydrophones which record seismoacoustic signals that cannot be detected by conventional short-period seismographs (Shurbet. 1962).

The study of $\mathrm{T}$-phases has never been a major research emphasis within the earth sciences: hence. even seismologists are generally unaware of their properties and characteristics. Perusal of some of the well-known text books in seismology reveals brief mention, if at all, of $\mathrm{T}$-phases $1 \mathrm{e} . \mathrm{t}$. . Aki and Richards. 1980; Bullen and Bolt. 19851. Much of the early T-phase research was performed in the late 1960s and early 1970s by a group of investigators at the Hawaii Institute of Geophysics who collected and analyzed data from the permanent. fixed hydrophone arrays of the Pacitic Missile Range/Missile Impact Location System installed in the late 1950, by the U.S. Air Force near the islands of Wake. Eniwetok. Midway. and

C.J. Brvan and C.E. Ninhimura. Naral Research Lahurators. Washingtun. DC 201375. CSA
Oahu (e.g.. Johnson of al., 1963: Norris and Johnson. 1969: Johnson and Norris. 1970). After this period of intense $T$-phase research, study of $T$ phases diminished.

Recent changes in the world's political climate and the willingness of the U.S. Navy to allow restricted access to acoustic data recorded by the Integrated Lndersea Surveillance System (ILSS) in both the Allantic and Pacitic Oceans have sparked a renewed interest in T-phase research. In Nowember 1492. the Space and Naval Warfare Systems Command and the Commander L'ndersea Surveillance Atlantic initiated a dual-use program (Whales ${ }^{\circ} 93$ ) through which U.S. Navy IUSS hydrophone data from the Atlantic Ocean were made arailable for scientitic study. The primary research goals of this program were 11 to study low-magnitude oceanic earthquakes and 2) to catalog the acoustic signals from large marine cetaceans to determine their spatial and temporal distributioms in the Atlantic Ocean. We discuss use of ILSS data in the monitoring and detection of oceanic earthquakes in the Atlantic Ocean with an example from the Caribbean. Detection and monitoring of oceanic earthquakes in the Pacitic Ocean is being carried out by the National Oceanic and Atmospheric Administrations: Pacitic Marine Environmental Laboratory. Details of early successes with that monitoring effort have been provided by Fox et al. (1994). Lxe of ILSS data for cetacean research has been previously discussed by Nishimura and Conlon (1994).

\section{Historical Perspective}

In 1941). Daniel Linehan reported the observation of a new seismic signal which originated from earthquakes along the western Antilles and was recorded on the seismographs of the Weston Observatory located at Buston. MA ILinehan. 1940). Because this signal arrived after the primary ( $P$ or compressional) and the secondary ( $S$ or shearl waves that travel through the solid earth. he aptly named his new discovery the tertiary or $\mathrm{T}$ phase. Although no qualitative explanation for the nature of the T-phase was given. Linehan specu- 
lated that this phase might be a slow propagating surface wave. This tentative explanation was later reiterated by Coulomb and Molard (1949) who proposed that $\mathrm{T}$-phases represented horizontally polarized shear (Love) wave propagation through sca floor sediment layers.

In the 1940s, research in the nascent field of ocean acoustics led to the recognition of the existence of a low-velocity layer within the oceans. This wave guide. named the SOFAR channel. focuses acoustic energy. thereby enabling long-range transmission of low-frequency waves. Much of this work was conducted by researchers affiliated with Columbia University and led to the publication of a classic treatise in underwater sound propagation (Ewing and Worzel. 1948). However, it was not until several more years had passed. a decade after the initial identification of the $T$ phase. that the hypothesis that the $T$-phase represents acoustic propagation through the oceans was first proposed (Tolstoy and Ewing. 1950).

Tolstoy and Ewing 's (1950) proposal initially met with much skepticism from the seismological community. the dominant objection being that the observed propagation velocities $11.6-2.7 \mathrm{~km} / \mathrm{s})$ were greater than the known speed of sound in water (e.g.. Leet at al. 1951). Other researchers argued that acoustic energy could not be efficiently coupled to ground motion recorded by land-hased seismographs (e.g.. Molard. 1952). Hence, these authors fawored alternative proposal in which $T$ phases represented Love wave propagation through the sedimentary layers that blanket the ocean floor 'Coulomb and Molard. 1949: Leet 't al. 1951: Molard. 19521. Much of this eriticism was laid to rest by the definitive work of Ewing 't al. 11952 , and Ewing and Press (1953) who showed that recording of $T$-phases on land-haved seismometers were clearly correlated with recordings on SOFAR hydrophones deployed off Point Sur. California and Kancohe. Hawaii. Furthermore. they showed that the dicrepancy hetween the observed velocities and the sound peed through water wa partially a reult of the manner in which T-phase arrival-times were chmen. They aloo pointed out that acoutic coupling between the ocean and the ground was not problematic if two mechanisms. SOFAR channel propagation athd normal mode propagation. were jointly responsible for T-phase propagation.

It is perhaps appropriate that in our initial foray into the study of $T$-phases. We return to the Caribhean region. the area from which the $T$ phases tirst observed by Linehan originated. The tectonics of thi region are controlled by complex interation among the North American. South American. Caribbean. Nazea. and Coco plater Molnar and Sykes. 1969) (Fig. 11. Our utudy focuses on the northeastern edge of the Caribbean plate in the vicinity of Puerto Rico and the Virgin Islands. In this region. North America-Caribbean plate motion is approximately parallel to the Puerto Rico trench (Frankel. 1981). and Atlantic sea floor is obliquely underthrust beneath the Caribbean plate (Fischer and McCann. 1984). To the east. Atlantic sea floor is underthrust beneath the Lesser Antilles island are (Molnar and Sykes. 1969: McCann and Sykes. 1984). while to the west. Hispaniola lies in a complex transition zone where plate motion ranges from oblique underthrusting on the east to strike-slip motion on the west (Molnar and Sykes. 1969: MicCann and Pennington. 1990).

Areas of intense seismic activity along the northeastern margin of the Caribbean plate correlate with the intersection of bathymetric highs on the subducting plate and the subduction zone (McCann and Sykes. 1984). Near Puerto Rico. there are two regions of particularly high seismicity (McCann. 1985). The tirst lies to the northwest of the intersection of the Mona Canyon with the Puerto Rico trench. The shallow crust in this region may be a portion of the Bahama Bank that was carried into the region by the North American plate and sutured to the Caribbean plate during the past few million years (McCann and Sykes. 1984). The second is the region to the northeas of Puerto Rico in which the aseismic Main Ridge meets the easternmont Virgin Islands. Similarly. in the Lesser Antilles. the internection of the Barracuda Ridge with the Lesser Antilles are is marked by a region of high seismicity (McCann and Sykes. $19 x+1$.

\section{SOSLS Data}

The spectrogram ifreyuenc!-time representation data used in this studs were recorded by ILSS hydrophone arrays operated by the L.S. Nats. The ILSS sistem convints of both the Sound Surveillance Sy tem (SOSLS) and the Surveillance Trued Array Senur Sylem ISLRTASS I Fig. 21. While SOSLS convist of passive. wean-hottom mounted hydrophones that transmit acou-tic igenal to land-based receiving and proewing vites via underwater cables. SLRTASS in a mohile w uned hehind a T-AGOS claw ship. Acoustic data collected with this stem are tramsmitted to procering sites lia secure satellite links.

\section{IISS Dual Ise: Earthquake Research}

Routine monitoring on 28 December 19y2 bs the L'S. Naly of its SOSLS hydrophone arrays in the Atlantic Ocean revealed the onset of intense seismic attivity north of the Virgin Islands. The SOSLS arras monitored at the Natal Ocean Procewing Facility INOPF, Dam Neck. VA. continued to record T-phases from this sequence during January 1993. with the arraty clonest to the T-phate surce region recording more than $100 /$ event per day for several weeks. The series of earthquakes included more than two dozen events of compressional body-(P-) wave magnitude $m_{k} \geq 4.0$. the
$I_{t}$ is perhaps

appropriate that . . .

we return to... the

area from which

the T-phases first

observed...

originated. 


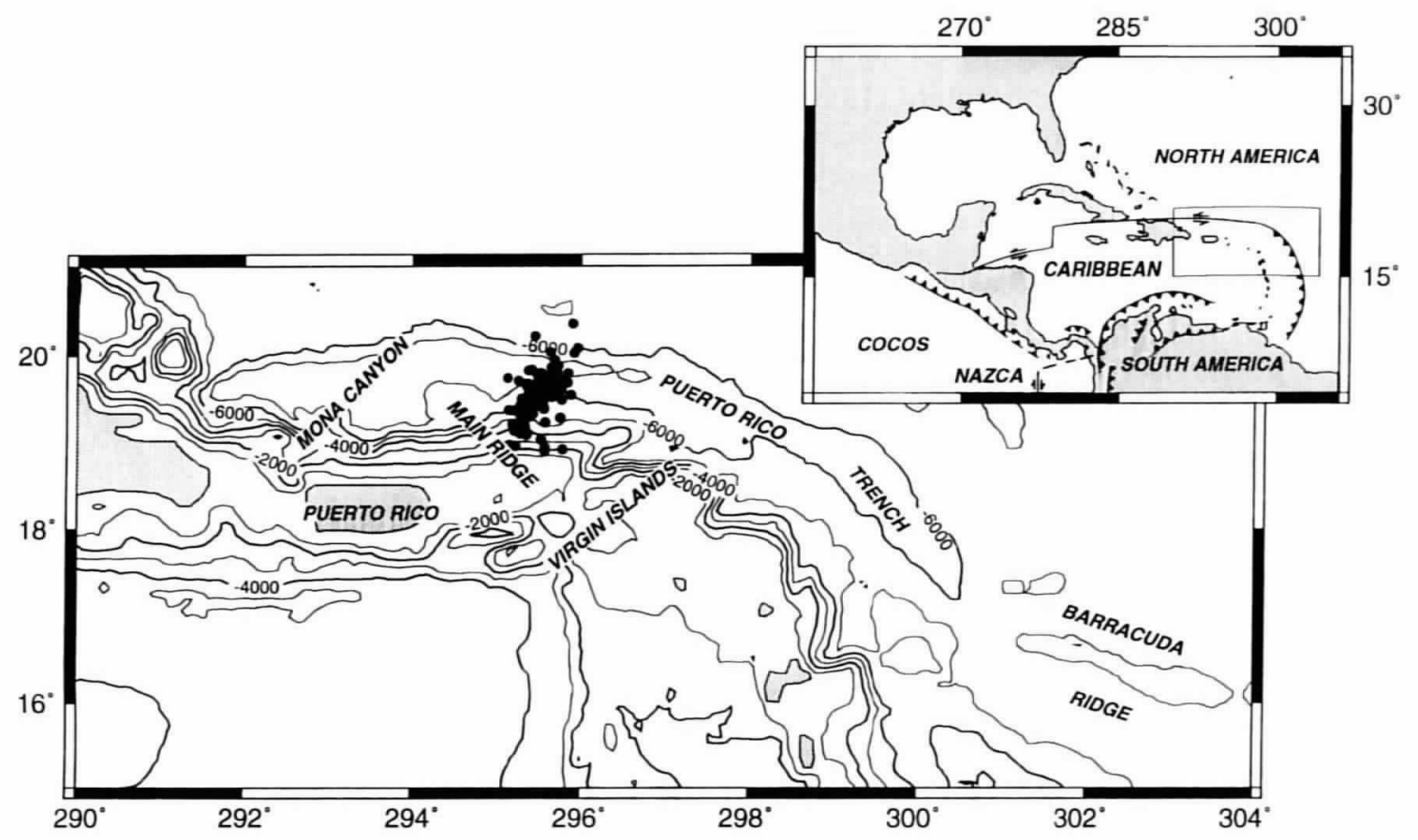

Fig. 1: Map of the Caribbean region. Bathymetric features discussed in the text are labeled. Contour interval is 1,000 m. Inset shows the North American, South American, Caribbean, Nazca, and Cocos plates. Plate boundaries are after Jordan (1975). Arrows indicate the direction of strike-slip motion while the teeth at the convergent boundaries indicate the direction of underthrusting of the subducting plate. The box shows the region of the larger map. Solid circles show well-constrained SOSUS locations for all earthquakes occurring between 19:20 UTC 28 December 1992 and 00:00 UTC I January 1993. The epicenters lie in the frequently active region near the intersection of the Main Ridge with the inner wall of the Puerto Rico Trench.

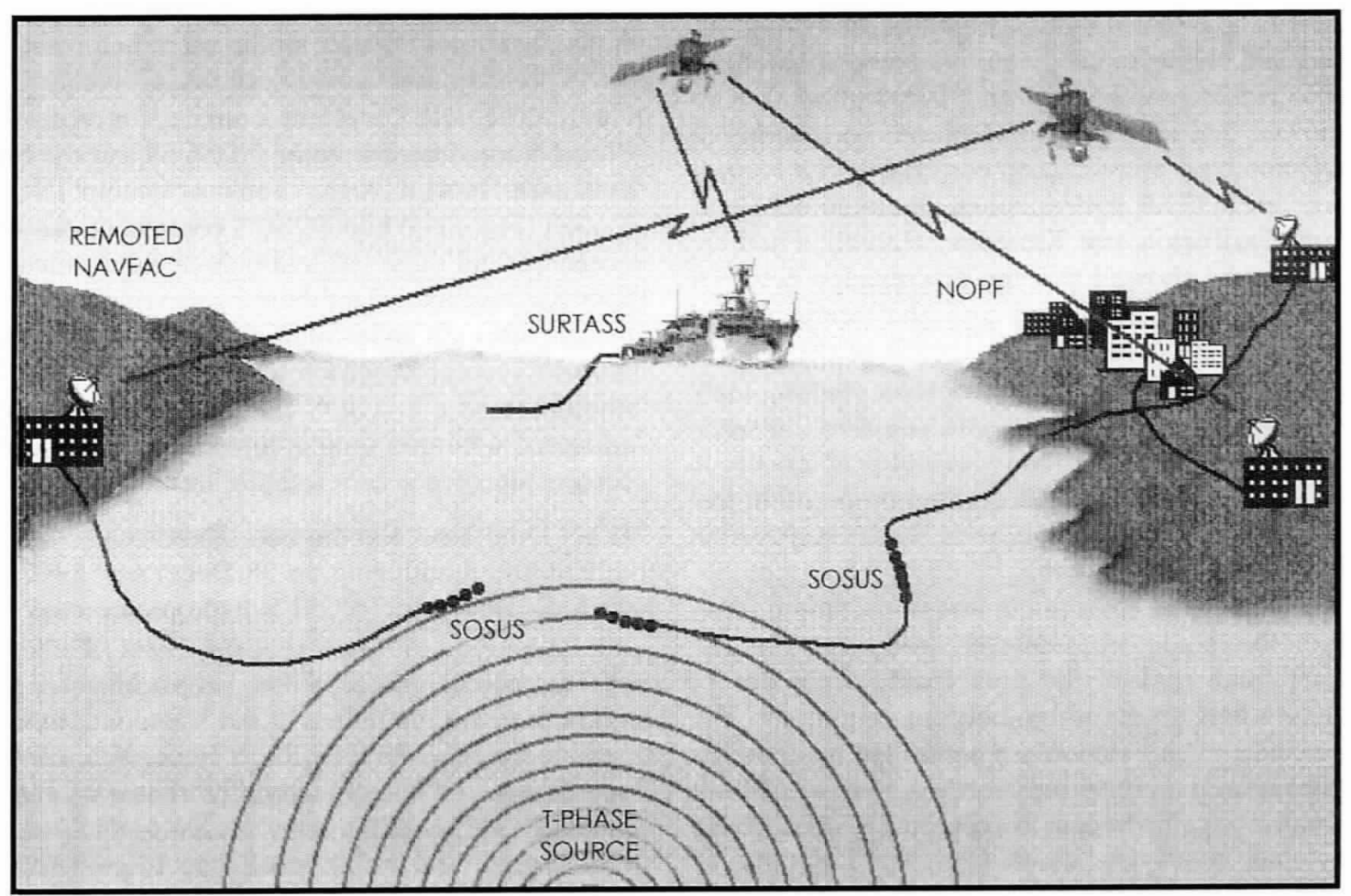

Fig. 2: Depiction of the Integrated Undersea Surveillance System (IUSS) showing both the Sound Surveillance System (SOSUS) and the Surveillance Towed Array Sensor System (SURTASS). 
largest of which were felt on St. Croix. St. John. St. Thomas, and Puerto Rico. While the largest events were recorded on all arrays monitored at NOPF. many of the smaller events were also recorded by a sufficient number of arrays to yield good epicentral locations. The geometry and number of hydrophone arrays from which data were made available for this study preclude the determination of hypocentral locations (latitude. longitude. depth. and origin time) for these events. In contrast. epicentral locations (latitude and longitude) are much more robust than hypocentral solutions when data are either sparse or otherwise inadequate (James et al., 1969: Gomberg et al.. 1990).

Signals from the U.S. Navy"s SOSUS arrays are routinely beam-formed at preset azimuths. thereby yielding directional information ( $\mathrm{Fig} .3$ ). Beam-forming also yields an increased signal-tonoise ratio relative to that from a single omnidirectional hydrophone. enabling the detection of lower magnitude events. Phases traveling at or near the speed of sound in water arrive from their true azimuth of approach. Solid-earth phases, such as $\mathbf{P}$ and $S$. which travel at much faster speeds than that of sound in water, arrive on the broad-side beams associated with any array. We exploit this information to identify compressional (P), shear ( $S$ ). and tertiary (T) phases for events from the Caribbean region. Sample spectrograms from three arrays with $\mathrm{P}$-. S-. and T-phases identified are shown in Figure 4. The numbers following the phase identifier correspond to events correlated across the arrays. While $\mathrm{T}$-phases were expected to be found on these records, the unexpected recording of the solid-earth $P$ - and S-phases greatly improved our ability to locate the events relative to that which would have been possible had only $T$-phases been recorded. Topographic shadowing of ARRAYl precludes the recording on this array of $T$-phases originating in the Caribbean region.

\section{Earthquake Counts}

In the 1960s. Shurbet demonstrated that SOFAR geophones situated adjacent to Bermuda recorded an order of magnitude more earthquakes than the short-period seismometers of the Bermuda-Columbia Seismograph Station IShurbet. 19621. Beam-forming from an array of hydrophones allows detection of smaller oceanic events than is possible with a single hydrophone.

The SOSLS arrays recorded two orders of magnitude more locatable events from the 1992-1993 Caribbean sequence than the landbased seismographs of either the World-Wide Standardized Seiumograph Network or the local Puerto Rico seismic network. A sample spectrogram howing detections during an intense 28 -h period at the array closest to the region of seismic activity is shown in Figure 5. Each vertical line represents a $\mathrm{T}$-phase from a different earthquake.

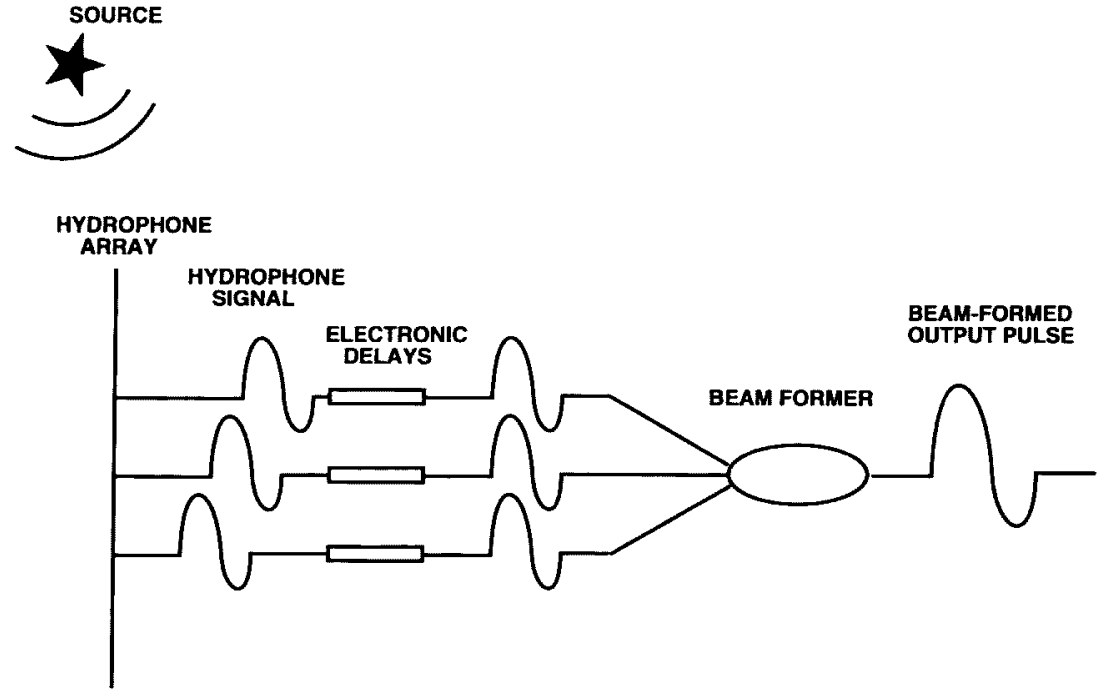

Fig. 3: Schematic showing the process by which signals from individual hydrophones are delayed and summed to form a beam-formed signal.

Counts of events by day for the first $34 \mathrm{~d}$ of the sequence are shown in Figure 6. Events are binned into 24-h periods beginning at 00:00:00 UTC. The number of events per day roughly falls into two groups. The beginning of the sequence on $28 \mathrm{De}$ cember 1992 was signaled by the occurrence of two events. $32 \mathrm{~min}$ apart. of $m_{h}=4.9$ and $m_{t}$ $=5.4$ (National Earthquake Information Center. 1993a). For the next few days. the daily number of events increased. reaching a peak on I January 1993. The ensuing overall decline in events continued until the occurrence of a $m_{k}=5.0$ event on 13 January 1993 (National Earthquake Information Center. 1993b). This event initiated a subsequent significant increase in seismicity. Similar to the overall pattern in the daily earthquake counts. the decline in activity following this $m_{r}=5.0$ earthquake followed the pattern typical of a main shock-aftershock sequence, rather than that of a seismic swarm.

\section{Event Location}

The accuracy of a T-phase source location is affected by the accuracy of the arrival-time estimates. knowledge of velocity structure along the travelpaths traversed by the seismic and acoustic waves. and the geometry of the hydrophone network with respect to the $\mathrm{T}$-phase source. The $\mathrm{T}$-phase arrivaltime is taken as the time at which the phase holds the highest frequency content. This arrival-time can be estimated to within 10 s for most events: due to the low propagation velocity of sound $1-1.5$ $\mathrm{km} / \mathrm{s}$ ) within the SOFAR channel. this yields a travel-path error of at most only $15 \mathrm{~km}$.

The hypocentral location of an earthquake does not alwats coincide with the $T$-phase radiation source, i.e., the location where seismic energy is converted to hydroacoustic energy. In general, these two locations diverge with increasing focal
The hypocentral

location of an

earthquake does not

always coincide with

the $T$-phase radiation

source. . . . 

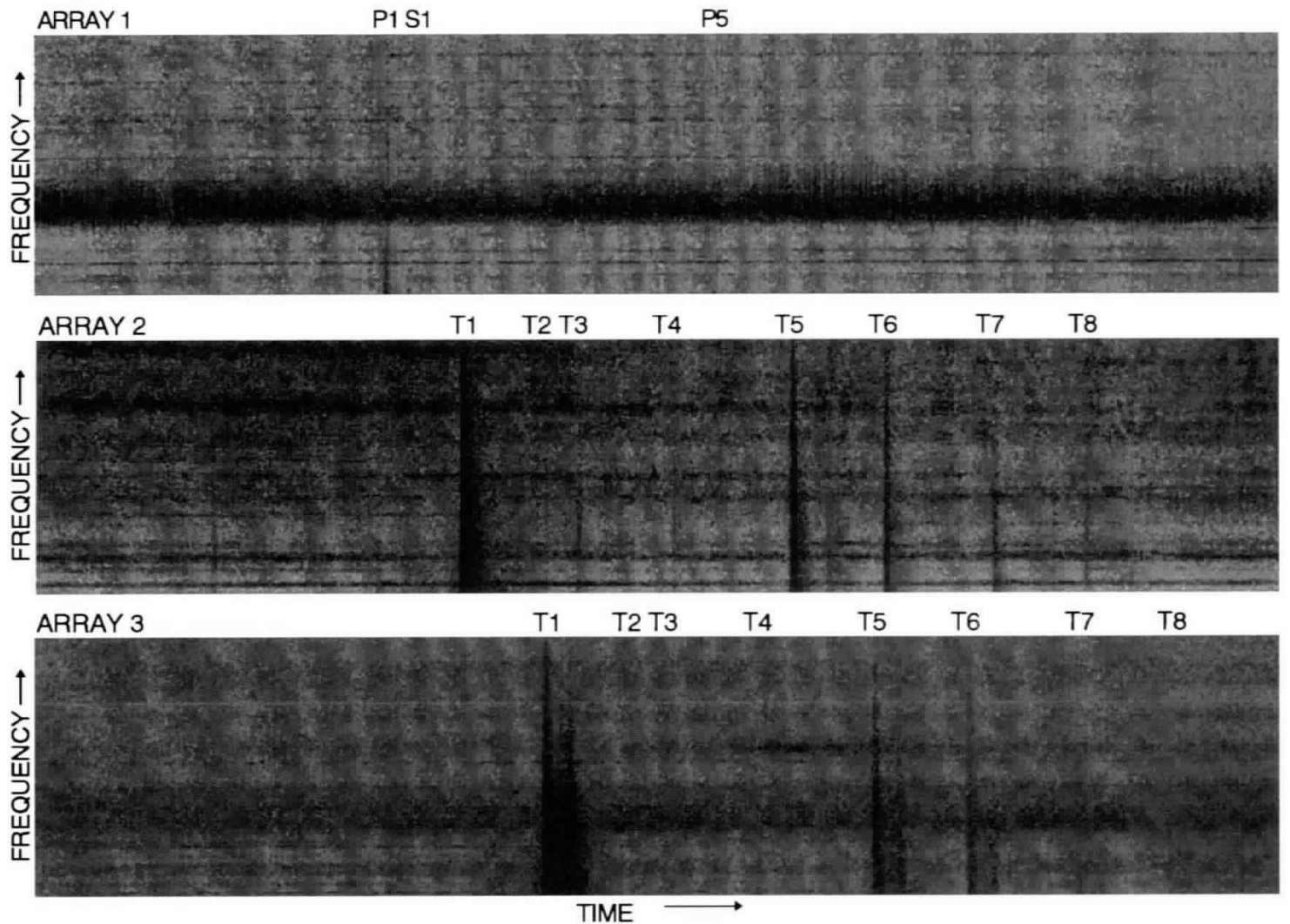

Inclusion of arrival

times from multiple

phases ... greatly

increases location

accuracy, . . . depths and in areas of high-relief bathymetry. We assume that these two source locations are colocated or, at least, are not significantly different, an assumption that we later verified. This assumption allows us to include $\mathrm{P}$ - and $\mathrm{S}$-wave arrival times in our inversion algorithm. Inclusion of arrival times from multiple phases at the same receiver greatly increases location accuracy, more than compensating for any degradation in the T-phase solutions that might result from including phases originating from slightly different source areas.

For any event for which we can pick approach directions for two or more T-phases, we use the directional (beam) information to calculate an initial location for the event. A schematic of this pro- cedure is shown in Figure 7. Our location algorithm then uses a weighted eigenvalue method to minimize simultaneously the sum of the squared residuals in both the beam and time data. Fast convergence of the location algorithm is enhanced by use of the a priori directional information in choosing the initial epicentral location. Figure 8 shows a comparison of our epicentral locations for events occurring between 19:20 UTC 28 December 1992 and 00:00 UTC 1 January 1993 with those given in the National Earthquake Information Center's (NEIC) Preliminary Determination of Epicenters (PDE) (1993a). Although we were able to obtain well-constrained locations for 188 earthquakes during the first $77 \mathrm{~h}$ of activ-

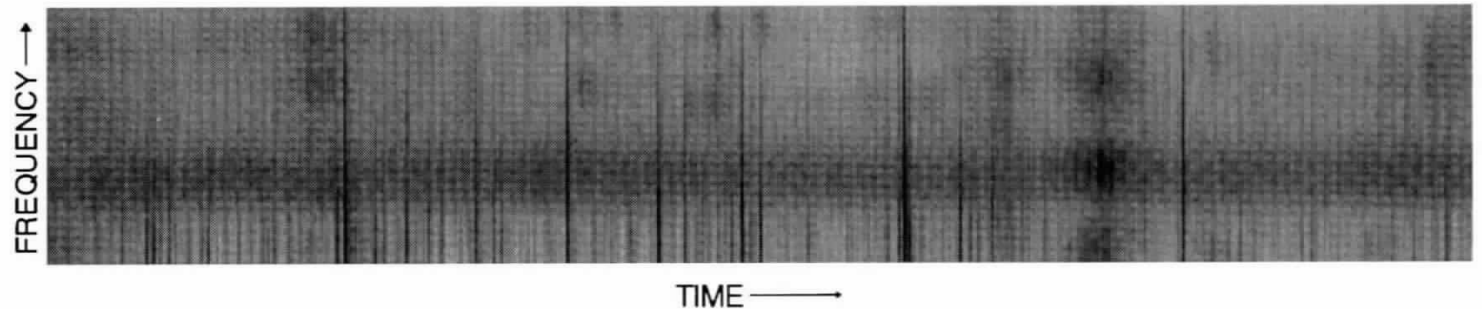

Fig. 5: A sample spectrogram showing T-phase detections during an intense 28-h period recorded at the array closest to the epicentral region. Arrows show the directions of increasing frequency and time. 


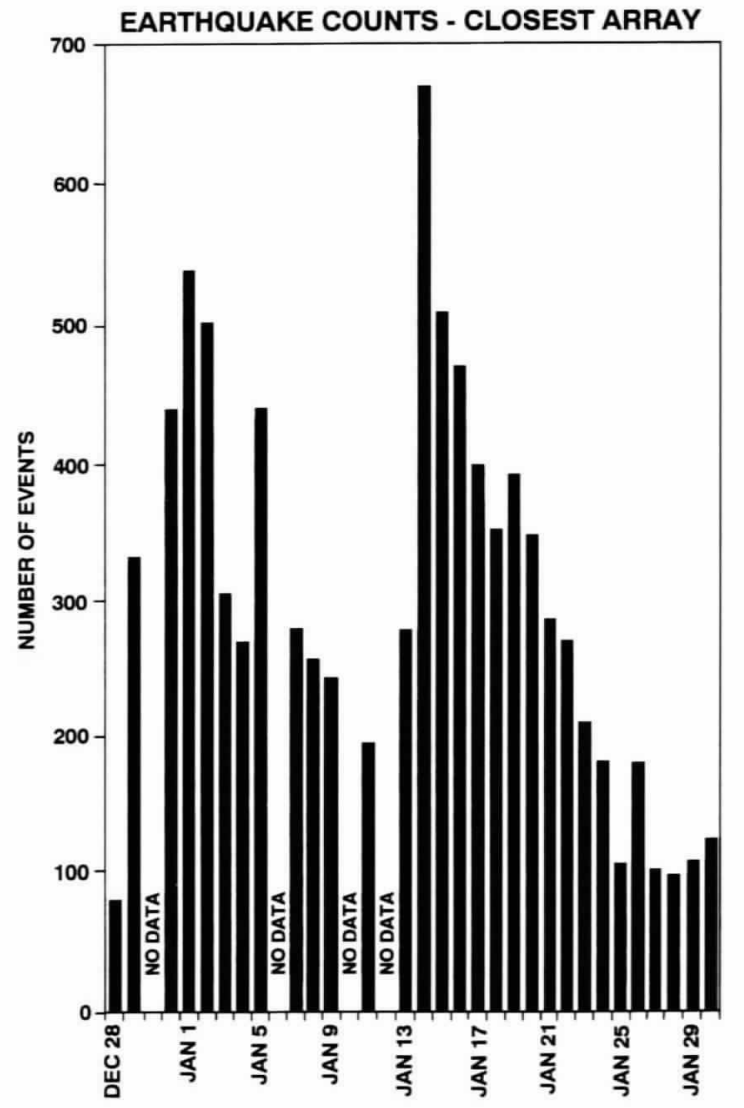

Fig. 6: Counts of earthquakes by day for the first 34 days of the period of intense seismic activity.

ity during this time period, the NEIC's PDE lists locations for only 12 events, while the Seismic Bulletin of the University of Puerto Rico lists preliminary locations for only 18 events (University of Puerto Rico, 1994). We point out again that the $\mathrm{T}$-phase solutions represent the radiation sources at which seismic energy is converted to hydroacoustic energy. These $\mathrm{T}$-phase radiation sources may not be coincident with the earthquake hypocenters and, in general, our solutions lie to the northeast of those given by the NEIC.

Figure 1 shows our well-constrained locations for all events detected by at least two arrays during the first $77 \mathrm{~h}$ of the sequence. In general, the epicenters lie in the frequently active region near the intersection of the Main Ridge with the inner wall of the Puerto Rico Trench. We cannot determine whether these events occurred within the Caribbean plate, the downgoing North American plate, or in the contact zone between the two plates.

\section{Discussion}

The recent release of U.S. Navy acoustic data through its dual-use program has made possible the real-time detection of low-magnitude oceanic seismic activity. Our preliminary results from a period of intense seismic activity in the Caribbean in late 1992/early 1993 indicate that the SOSUS hydrophones are capable of detecting two orders

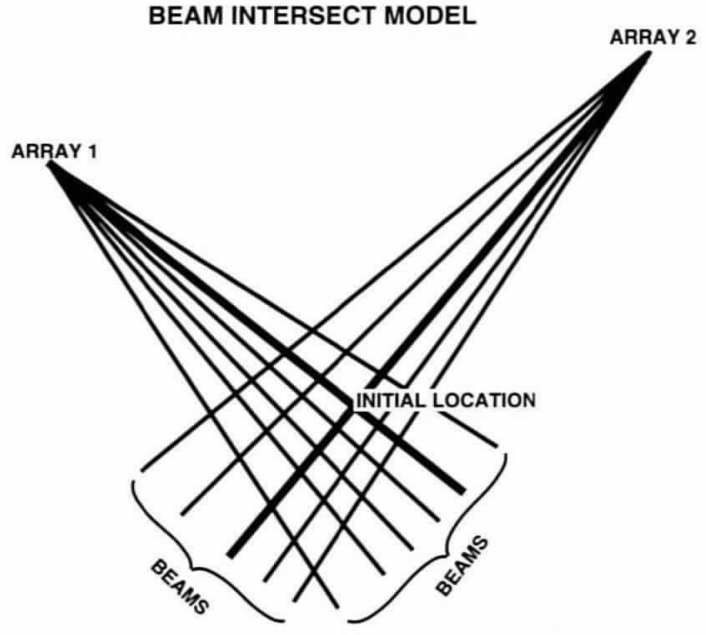

Fig. 7: Schematic diagramming how directional information from two hydrophone arrays is used to determine an initial location for an earthquake.

of magnitude more small oceanic earthquakes than are recorded by land-based seismographs. Other authors (e.g., Walker and McCreery, 1985; Cessaro and Walker, 1988) have remarked on a similar result for other oceanic areas; however, it should be noted that oceanic earthquakes not reported in publications of the National Earthquake Information Center or the International Seismological Center, and, by extension, other seismological services, may have been recorded but excluded from the corresponding seismic bulletins due to uncertainty in the event location or because of incorrect associations of earthquake phases with those from other events (Muirhead and Adams, 1986).

T-phase source solutions for events which occurred during the first four days of the Caribbean activity generally lie to the northeast of the epicenters of the associated earthquakes as given by the NEIC. This may be a reflection of the fact that a $\mathrm{T}$-phase source solution represents the location of

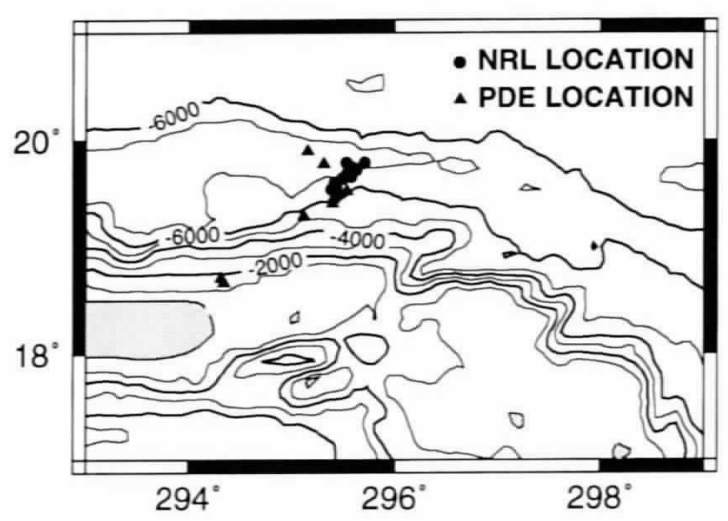

Fig. 8: Comparison of our epicentral locations for events occurring during the first $77 \mathrm{~h}$ of intense seismic activity with those listed in the NEIC's PDE (1993a).

\section{T-phase}

solutions represent

the radiation sources

at which seismic

energy is converted

to hydroacoustic energy. 
the conversion of seismic energy to hydroacoustic energy and need not be coincident with the associated earthquake's hypocenter. More detailed seismoacoustic propagation modeling. which is beyond the scope of this initial study. must be performed to understand better the mechanism by which $\mathrm{T}$-phases are generated.

\section{Acknowledgments}

We thank Cmdr. Dale Liechty and Dr. Dennis Conlon of SPAWAR and Lcdr. Lysa Olsen of CUSL for inviting us to participate in the Whales ' 93 program and allowing us access to the wealth of SOSUS data. Lcdr. Chuck Gagnon and the Ocean Technician Analysts of the Naval Ocean Processing Facility. Dam Neck. VA provided invaluable assistance in the initial analysis of the data and in the data archiving. Comments from two anonymous reviewers improved this manuscript. I. Jewett assisted with the preparation of some of the figures. This work was performed while C. Bryan held a National Research Council-Naval Research Laboratory Research Associateship.

\section{References}

Aki, K. and P.G. Richards. 1980: Quantitatice Seismology: Theory and Methods, wol. 1. W.H. Freeman. San Francisco. $557 \mathrm{pp}$.

Bullen. K.E. and B.A. Bolt. 1985: An Intrudiction to the The'ory of Scismolngy. Cambridge Lniversity Press. Cambridge. England. $499 \mathrm{pp}$.

Cessaro. R.K. and D.A. Walker. 1988: Significant unreported earthyuakes in subducting margins of the northwestern Pacific basin. Scism. Res. Le't. 59. 25.

Coulomb. J. and P. Molard. 1949: Ondes séismiques au fond de la mer des Antilles, Am. Geophys., 5, 212-214.

Eving. M. and F. Press. 1953: Mechanisms of T wave propagation. Am. Gerphy.. 4. 248-249.

F. Press and J.L. Worzel, 1952: Further study of the T phase. Bull. Seism. Soc. Am., f2, 37-51. and J.L. Worzel. 1448: Long-range sound transmission. In: Propagation of Sound in the Ocean. Geological Society of America Memoir 27. The Geological Society of America. New York. $35 \mathrm{pp}$.

Fischer, K.M. and W.R. McCann. 1984: Velocity modeling and earthquake relocation in the northeast Caribbean. Bull. Seism. Sire. Am. 74, 1349-1262.

Fox, C.G. R.P. Driak. H. Matsumoto and A.E. Schreiner, 1994: Potential for monitoring low-level seimicity on the Juan de Fuca Ridge using military hydrophone array. Mar. Tech So. J., 27. 22-30.

Frankel. A., 1981: Source parameters and scaling relationships of small earthquakes in the northeastern Caribbean. Bull. Seism. Soc. Am. 7/. 1173-1190.

Gomberg. J.S.. K.MI. Shedlock and S.W. Roecher. 1990: The effect of $S-w a v e$ arrival times on the accurasy of hypocenter estimation. Bull. Seism. Six. Am. No. 1605-162x

James. D.E.. I.S. Sacks. E. Lazo. L. and P. Aparicio G. 1969: On lovating local earthquakes using small networks. Bull. Stism. Sor. Am. 54. 12011-1212.

Johnson, R.H. and R.A. Norrin. 1970: T-wase generation mechaninms. Hawait Institute of Geophysics Report. $H I G-701.7 .50 \mathrm{pP}$.

1. Northrop and R. Fpples. 1963: Sources of Palcitic T phases. 1. Gooplys. Res. 6s. 4251-4260.

Jordan. T.H.. 1975: The present-day motions of the Caribbean plate. J. Geryphs. Re's.. No. 4433-1439.

Leet. L.D., D Linehan and P.R. Berger. 1951: Invextigation of the T phane. Bull. Seivm. Sex. Am. +1, 123-141.

Linehan. D., 1940: Earthyuakes in the West Indian region. Truns. Anter. Getphy. Linion. 21. 229-232.

MLCann. W.R.. I985: On the earthyuake halards of Puerto Rico and the Virgin Islands. Bull. Serism. Sre. Am. 75, 251-262 and W.D. Pennington. 1990): Seismicity. large earthquakes, and the margin of the Caribbean plate. In: The Geveng of North America. wol. H. The Caribhean Re. gion. G. Dengo and J.E. Case. eds. The Geolongial Sor ciety of America. Boulder. CO. 291-306.

and L.R. Sykev, 1484: Subduction of aseismic ridges heneath the Caribbean plate: implications for the tecunics and seismic potential of the northeastern Caribhean. J. Geophm. Re's.. 89, $493-4519$

Molard. P. 1952: Remarques au sujet des ondes T. Amm. Gevphys. 6. 335-336.

Molnar. P. and L.R. Sykes. 1964: Tectonics of the Caribbean and Middle America regions from focal mechanisms and seismicity. Geol. Sor. Am. Bull.. kfl, 1639-1684.

Nuirhead, K. and R.D. Adams, 1486: Earthquakes in the "aseinmic" regions of the wentern Patific. Geophss. $R_{\mathrm{t}^{2}}$. Le'll. IS. 169-172.

National Earthquake Inlormation Center. 1993a: Preliminary Determination of Epicenters. Monthly Listing. December 1992. ['.S. Gusemment Printing Otfice 1943-838$99(1,30 \mathrm{pm}$

1943b: Preliminary Determination of Epicenters. Monthly Livting. January 1993. U.S. Government Printing Office 1993-839-146. 39 pp.

Nishimura. C.E. and D.M. Conlon. 1944: It'SS dual use: monitoring whalev and earthquakes using SOSUS. Mar. Tech. Su: J. 2: $13-21$

Norris. R.A. and R.H. Johnton. 1969: Suhmarine volcanic eruption recenty lociled in the Pacitic by Sofar hydrophones. I. Geophrs. Res. 74. 650-6ht.

Shurbet. D.H. 1962: Note in use of a SOFAR geophone 11 determine seismicity of regional oceanic areas. Bull. Serm. Sex. Am. 52, 689 691

Tolsoy. I. and M. Ewing. 1950: The T phase of shallow-focu earthquakes. Bull. Seimm. S(x. Am., 40, 25-51.

University of Puerto Rico, 1994: Seismic Bulletin. Preliminary locations of earthquakes recorded near Puerto Rico. $\mathrm{O}^{2}$ tober-December. 1992. Mayague/ Campus. Department of Geolog?. Seimic Network. $149 \mathrm{pp}$.

Walker. D.A and C.S. MeCreery. 1985: Significant unrepurted earthquakes in "ascismic" regions of the western Pacitic. Gerephys. Re's. Lest. I2. 433-436. 口 